\title{
The investigation of ethanol separation by the membrane distillation process
}

\author{
Maria Tomaszewska, Lidia Białończyk \\ West Pomeranian University of Technology, Szczecin, Institute of Chemical and Environment Engineering, \\ ul. Pułaskiego 10,70-322 Szczecin, Poland, e-mail: maria.tomaszewska@zut.edu.pl
}

\begin{abstract}
Separation of ethanol from solutions with different concentrations in a BIOTRON bioreactor integrated with the direct contact membrane distillation system has been investigated. The experiments were carried out using immersed, capillary polypropylene membranes. The permeability of the membrane at the feed inlet temperatures of 308, 318 and 333K was determined. The permeate and ethanol flux was strongly affected by the vapour pressure which increased with the feed temperature and it was also associated with ethanol concentration in the feed. It was found that the membrane distillation can be successfully applied for the separation of volatile components such as ethanol.
\end{abstract}

Keywords: membrane distillation, bioreactor, ethanol, immersed capillary membranes.

\section{INTRODUCTION}

Sooner or later, fossil fuels such as oil, coal and natural gas will be exhausted. We should, therefore, make practical use of other energy sources ${ }^{1}$. The production of bioethanol from renewable resources such as cellulose-rich organic materials (straw, wood) or agricultural by-products (molasses, whey) has been considered as a promising technology, especially in the transport sector ${ }^{1}$. Ethanol can also be generated as a by-product of biological transformations. The synthesis of 1,3-propanediol from glycerol using microorganisms can serve as an example ${ }^{2}$. At higher concentration ethanol reduces the microorganisms performance. The removal of ethanol reduces inhibition and it could be the reason for the higher efficiency of 1,3-propanediol production.

Ethanol fermentation can convert the biomass into a useful energy source as pure ethanol or gasohol ${ }^{1}$. However, the ethanol production by the conventional process of a batch fermentation of sugars with yeast, followed by distillation to recover the ethanol is uneconomic in comparison with fossil fuels ${ }^{\mathbf{3}, 4}$. Among many microorganisms that have been exploited for ethanol production, Saccharomyces cerevisiae still remains as the prime species. The membranes technologies as highly selective and energy-saving unit operations have a great potential in the bioethanol industry ${ }^{6}$. Together with economic aspects, the membrane technologies have been proposed as an alternative to the conventional separation processes. The separation of ethanol from the fermentation broth may be successfully performed by membrane distillation (MD) or pervaporation $(\mathrm{PV})^{7}$.

Membrane distillation is a process in which the hot feed solution evaporates and the vapour diffuses through the pores, and undergoes condensation on the opposite side of the membrane. In the direct contact MD (DCMD) the feed is in a direct- contact with a hydrophobic porous membrane and the permeate is directly condensed in the cooling stream flowing along the membrane surface. Non-volatile solutes contained in the feed are completely retained by the membrane ${ }^{8}$. The driving force for mass transfer is the difference in vapour pressure between the feed and the permeate side of the membrane'. During the MD of ethanol solution the vapour pressure of ethanol is higher than water, therefore, the ethanol vapour is transferred preferentially through the membrane pores than the water vapour due to the partial pressure gradient existing across the membrane ${ }^{\mathbf{1 0 , 1 1}}$. The application of the bioreactor coupled with the MD system enables to achieve a distillate enriched with ethanol ${ }^{12}$.

The objective of these studies was to determine the advantageous parameters of bioreactor operation coupled with DCMD during the separation of ethanol from the solutions with different concentrations. The influence of the feed composition on the magnitude of ethanol flux through the immersed capillary membrane was determined.

\section{EXPERIMENTAL}

The experiments were carried out using the BIOTRON bioreactor integrated with the direct contact membrane distillation system, shown in Fig. 1. The capillary module made from polypropylene membrane (PP) (Membrana $\mathrm{GmbH}$, Germany) was used in the studies. The outside and inside diameter of the capillary membranes were 2.6 and $1.8 \mathrm{~mm}$, respectively. The effective area of mass transfer amounted to $0.0183 \mathrm{~m}^{2}$.

The membranes were directly immersed in an ethanol solution (feed) in a bioreactor tank. The bioreactor agitated vessel was equipped with a high speed agitator. The membranes were located around the agitator in the way protect-

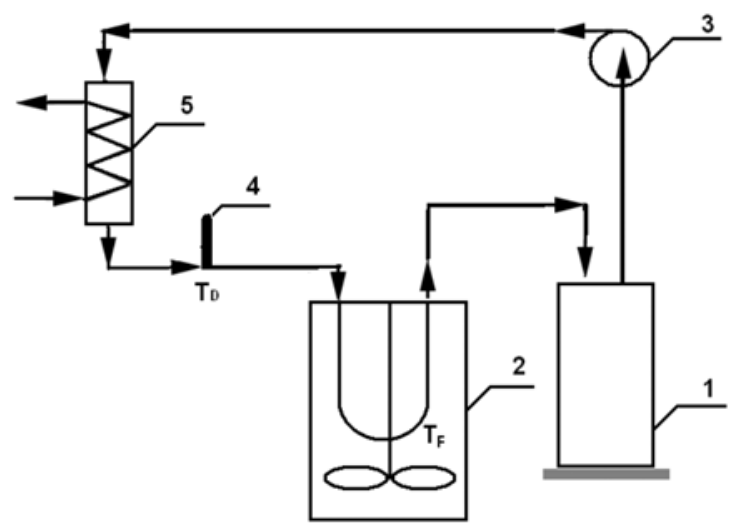

Figure 1. Scheme of the experimental apparatus. 1 - distillate tank, 2 - bioreactor with capillary module, 3 - pump, 4 - thermometer (TD-temperature of the distillate), 5 - cooling system 
ing them against mechanical damage. The ethanol solution in the bioreactor was agitated to restore the layer of the feed adjacent to the membrane surface. The peristaltic pump supplied the distillate from the distillate tank, through a cooling system to the interior of the capillary membranes. Ethanol and water evaporate during the process and the vapour diffuse through the air filling membranes pores and then condensate directly in the cold distillate stream (direct contact MD).

The studies of ethanol separation were performed using model solutions. The aqueous solutions of ethanol at concentrations: $10,20,50,70,100 \mathrm{~g} \cdot \mathrm{dm}^{-3}$ and distilled water were used as a feed. The initial mass of ethanol solutions used as the feed was $2750 \mathrm{~g}$. The experiments were carried out at the feed temperatures of 308, 318 and $333 \mathrm{~K}$. The inlet temperature of the cold distillate was kept at $293 \mathrm{~K}$ for all the experiments. The cold system was initially supplied by $700 \mathrm{~g}$ of distilled water. The flow rate of distillate was $105 \mathrm{~cm}^{3} \cdot \mathrm{min}^{-1}$. The MD process was run for 5 hours. After each experiment the feed was replaced by distilled water and the MD installation was rinsed.

The temperature and the mass of the feed and distillate were measured every hour and the permeate flux (vapour flux through the membrane pores), $J$, was calculated from the equation:

$J=\frac{\left(m_{t+1}-m_{t}\right) \cdot 24}{A t \cdot 1000} \quad\left[\mathrm{~kg} \cdot \mathrm{m}^{-2}\left(24 h^{-1}\right)\right]$

where:

$m_{t+1}$ - mass of distillate at time $\mathrm{t}+1[\mathrm{~g}]$

$m_{t}-$ mass of distillate at time $\mathrm{t}[\mathrm{g}]$

$A$ - membrane area outside capillaries $\left[\mathrm{m}^{2}\right]$

$t$ - time $[h]$

The ethanol concentration was determined both in the distillate and feed. The distillate comprised distilled water initially placed in the cold system together with the water and ethanol vapour condensed in the cold solution. Analysis of ethanol concentration in the solutions was performed using an Abbe refractometer. The ethanol flux, $J_{E}$, was calculated from the material balance of ethanol in the distillate performed every hour taking into account the changes of the mass and the ethanol concentration in the distillate:

$J_{E}=\frac{\left(C_{t+1} \cdot m_{t+1}-C_{t} \cdot m_{t}\right) \cdot 24}{d \cdot A \cdot t \cdot 1000} \quad\left[\mathrm{~kg} \cdot \mathrm{m}^{-2}(24 h)^{-1}\right]$

where:

$C_{t+1}$ - distillate concentrations at time $t+1\left[\mathrm{~g} \cdot \mathrm{dm}^{-3}\right]$

$C_{t}$ - distillate concentrations at time $t\left[\mathrm{~g} \cdot \mathrm{dm}^{-3}\right]$

$m_{t+1}-$ mass of the distillate at time $t+1[\mathrm{~g}]$

$m_{t}-$ mass of the distillate at time $t[\mathrm{~g}]$

$A$ - membrane area outside capillaries $\left[\mathrm{m}^{2}\right]$

$t$ - time $[h]$

$d$ - distillate density at time $\left[\mathrm{g} \cdot \mathrm{dm}^{-3}\right]$

Moreover, taking into account the permeate flux and the changes of ethanol concentration in the distillate, the ethanol concentration in the permeate, $C_{p}$, was calculated from the equation:

$C_{p}=\frac{\left(C_{t+1} \cdot m_{t+1}-C_{t} \cdot m_{t}\right)}{m_{t+1}-m_{t}} \quad\left[\mathrm{~g} \cdot \mathrm{dm}^{-3}\right]$

where:

$C_{t+1}-$ distillate concentrations at time $t+1\left[\mathrm{~g} \cdot \mathrm{dm}^{-3}\right]$

$C_{t}$ - distillate concentrations at time $t\left[\mathrm{~g} \cdot \mathrm{dm}^{-3}\right]$ $m_{t+1}-$ mass of the distillate at time $t+1[\mathrm{~g}]$

$m_{t}-$ mass of the distillate at time $t[\mathrm{~g}]$

The vapour pressure of pure component $p^{*}{ }_{i}$ was calculated from the Antoine equation ${ }^{\mathbf{1 3}}$ :

For ethanol:

$\log p_{E}^{*}[m m H g]=8.1629-\frac{1623.22}{228.98+t_{i}}[\operatorname{Tr}]$

For water:

$\log p_{w}^{*}[m m H g]=8.07131-\frac{1730.63}{233.42+t_{i}}$

where $t_{i}$ is temperature $\left[{ }^{\circ} \mathrm{C}\right]$.

\section{RESULTS AND DISCUSSION}

A preliminary investigation of vapour transfer through the PP membrane was carried out using distilled water as a feed. These experiments permitted to determine the bioreactor profitable working conditions with immersed membranes and to determine a permeate flux (water) through the membrane.

The studies of the influence of the agitator speeds in the bioreactor on the permeate flux were previously performed. The flow rate of a solution around a capillary membrane during mixing of a feed solution depends on the intensity of agitator speeds and has an influence on the phenomenon of temperature polarization. The maximum values of permeate flux were measured when the bioreactor agitator speed amounted to $400 \mathrm{rpm}$. When the agitator speed was higher, the lack of stability in the bioreactor operation was observed and the permeate flux decreased (the results were not presented here).

The results shown in Fig. 2 indicated that the permeate flux across the membrane was on a constant level at the given temperature during the MD process and increased with the feed temperature. The permeate flux for water used as a feed increased from $19.7 \mathrm{~kg} \cdot \mathrm{m}^{-2} \cdot(24 \cdot \mathrm{h})^{-1}$ at $308 \mathrm{~K}$ to $105.0 \mathrm{~kg} \cdot \mathrm{m}^{-2} \cdot(24 \cdot \mathrm{h})^{-1}$ when the feed temperature was $333 \mathrm{~K}$. The changes of the permeate flux for the distilled water and the ethanol solutions with temperature are presented in Fig. 3. As can be seen, the course of curves for distilled water and ethanol solution had a similar exponential character. These results strongly depended on the vapour pressure of water and ethanol which increased when the feed temperature was higher.

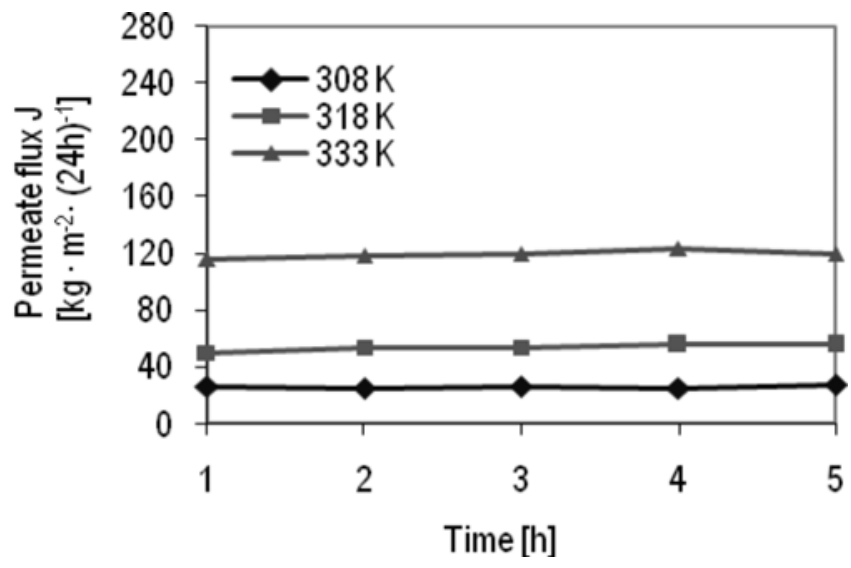

Figure 2. Changes of permeate flux for distilled water as a function of the MD process time 
Due to the fact that ethanol is volatile, for ethanol solution used as a feed, the permeate flux in MD is a sum of water and ethanol flux (in a vapour form) through the hydrophobic membrane.

The influence of ethanol concentration in the feed on the permeate flux through the membrane in the membrane distillation process was examined. The ethanol solutions with the initial concentration of $10,20,50,70$ and 100 $\mathrm{g} \cdot \mathrm{dm}^{3}$ were used as a feed. As it can be seen in Fig. 3, the permeate flux through the membrane increased in the case of the feed with higher initial ethanol concentration. This was caused by a significantly higher the partial pressure of ethanol vapour than the water partial pressure over ethanol solution (Fig. 4). Moreover, the differences between the vapour pressure of ethanol and water, increased with temperature very fast.

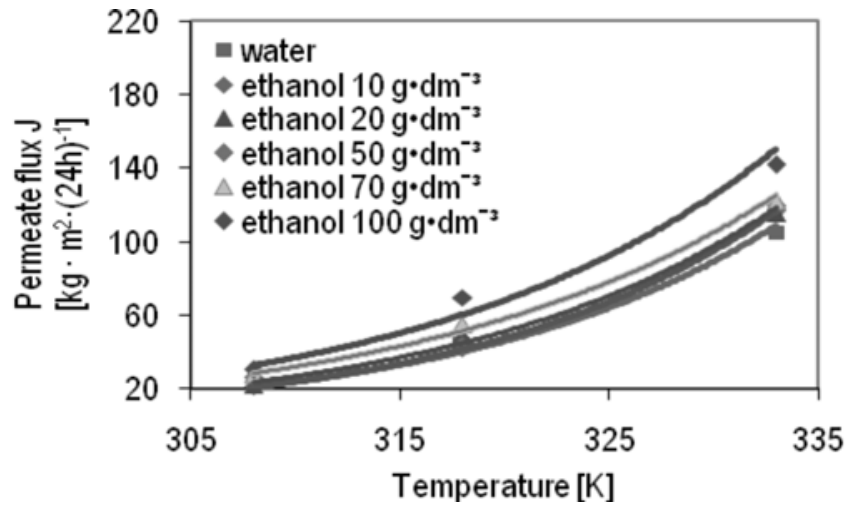

Figure 3. Changes of the permeate flux for the distilled water and ethanol solution with initial concentration $10,20,50,70,100 \mathrm{~g} / \mathrm{dm}^{3}$ at different feed temperature

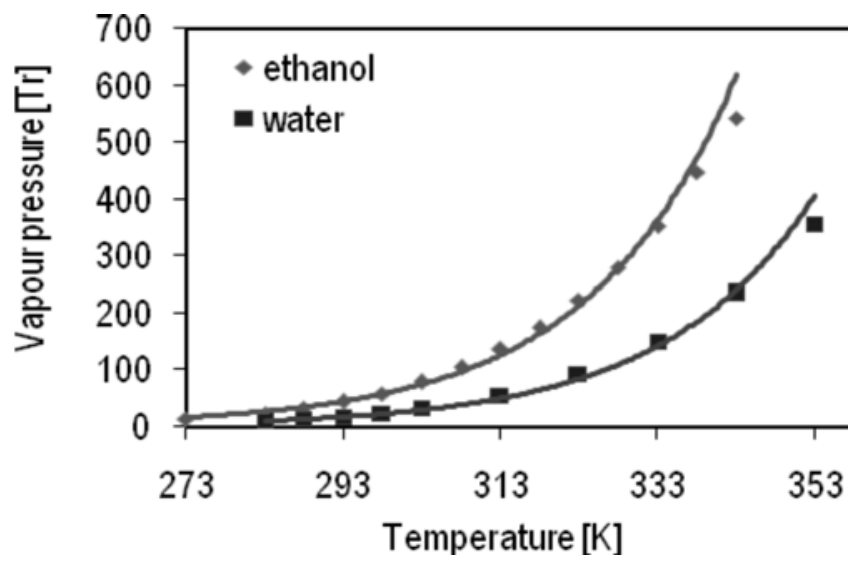

Figure 4. The dependence of the water and ethanol vapour pressure over ethanol solution as a function of the temperature ${ }^{14}$

Figure 5 presents the dependence of the final permeate flux of distilled water and the ethanol solution with an initial concentration equal to $70 \mathrm{~g} \cdot \mathrm{dm}^{3}$ on the vapour pressure of water and ethanol over these solutions during MD, calculated for temperatures 308, 318 and $333 \mathrm{~K}$. The bioreactor agitator speed amounted to $400 \mathrm{rpm}$. The data show that the permeate flux for the distilled water and ethanol solution with the initial concentration $70 \mathrm{~g} \cdot \mathrm{dm}^{3}$ as a function of vapour pressure for different process temperatures was practically on a constant level. It confirms the state that the used agitator speed caused a slight influence of the temperature polarization on the mass transfer.

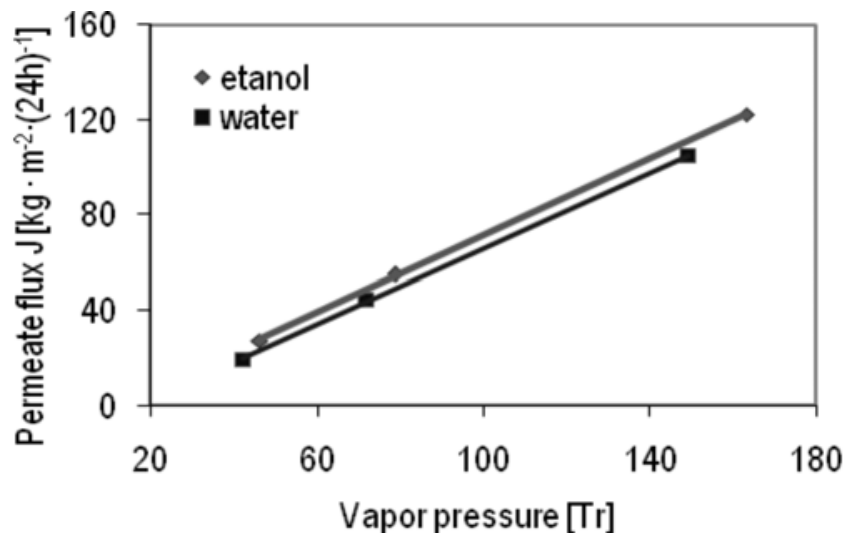

Figure 5. Changes of permeate flux for distilled water and ethanol solution with initial concentration $70 \mathrm{~g} / \mathrm{dm}^{3}$ as a function of the vapour pressure

The changes of ethanol concentration in the feed during MD are shown in Fig. 6. During the ethanol separation from the feed by MD, both water and ethanol vapour were transported through the hydrophobic membrane pores. Due to that the ethanol concentration in the feed was gradually decreased. These results were dependent on the feed temperature. With an increase of temperature, the ethanol vapour pressure over the solution was so high that the ethanol concentration in the feed decreased in spite of the concentration process. However, at a lower feed concentration, the ethanol vapour pressure was also lower, thus the driving force decreased and the resultant ethanol concentration in the permeate was lower at higher feed temperature. The water vapour pressure was high under these conditions and the water flux through the membrane (in the vapour form) was high. A constant flux of water and simultaneously lower driving force of ethanol due to its lower concentration in the feed, caused the reduction of the ethanol concentration in the permeate. The largest decrease of the ethanol concentration in the feed was at $333 \mathrm{~K}$.

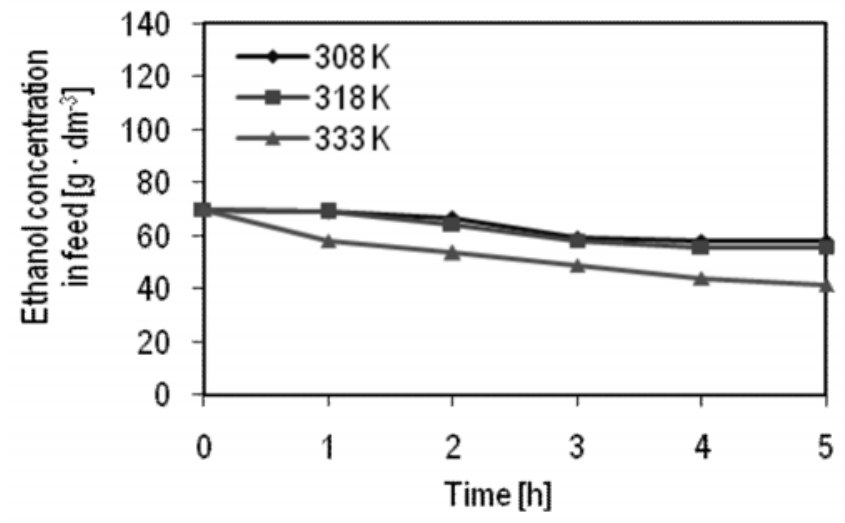

Figure 6. Changes of ethanol concentration in the feed as a function of the MD process time (initial concentration of ethanol solution was $70 \mathrm{~g} / \mathrm{dm}^{3}$ )

The ethanol concentration in the permeate was a reflection of its changes in the feed. The changes of ethanol concentration both in the feed and permeate (Fig. 7) were considerably higher during the first hours of MD process, which was associated with a higher value of the driving force for the ethanol transport through the MD membrane. Together with a gradual decrease of ethanol concentration in the feed and an increase of its concentration in the 


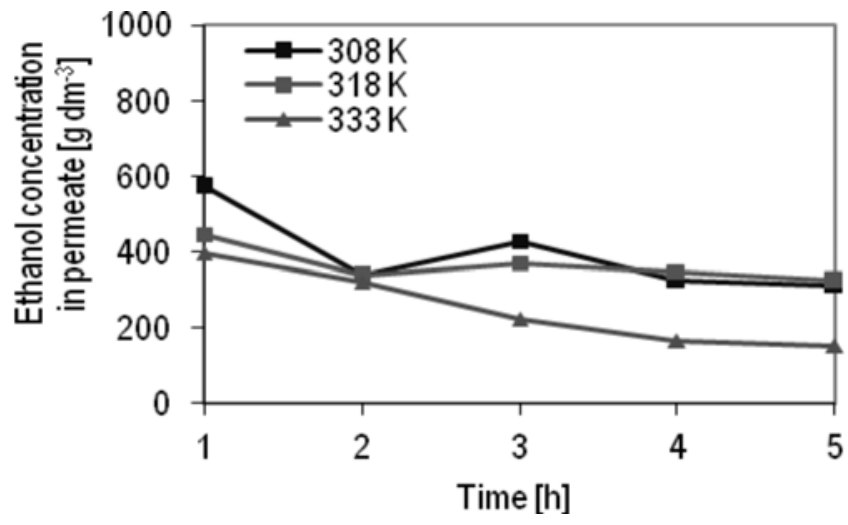

Figure 7. Changes of ethanol concentration in permeate as a function of the MD process time (initial concentration of ethanol solution was $70 \mathrm{~g} / \mathrm{dm}^{3}$ )

distillate, the driving force of the MD process decreased and the changes of permeate flux were smaller. The process proceeded despite the lower concentrations of ethanol in the feed than that in the distillate.

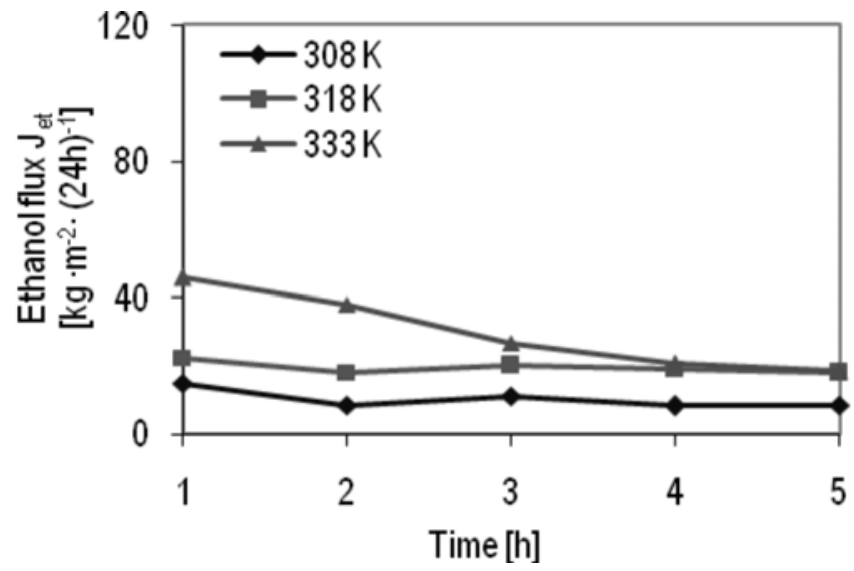

Figure 8. Changes of ethanol flux as a function of the MD process time. Initial ethanol concentration of the feed was $70 \mathrm{~g} / \mathrm{dm}^{3}$

The changes of ethanol flux through the membrane as a function of time of the MD process are shown in Fig. 8. It was found that the highest value of the ethanol flux was achieved at first hour of the process. During the MD process the ethanol concentration in the feed decreases, therefore the permeate flux through the membrane pores also decreased in time. The higher ethanol flux was obtained at higher temperatures (Fig. 8).

\section{CONCLUSIONS}

The flux and the composition of the permeate during MD ethanol solution strongly depends on the temperature and the composition of the feed.

Intensive stirring of the feed during MD experiments in the membrane bioreactor significantly reduced an influence of the temperature polarization on the mass transfer.

High temperature of the feed caused the increase of the ethanol partial pressure on the feed side and the resultant driving force. At the higher temperature of the feed the ethanol vapour transfer was so high that the ethanol concentration on the feed side decreased. Simultaneously, the ethanol concentration in the permeate was lower under such conditions.

The results of the studies indicated that ethanol can be effectively separated by MD even from diluted solutions.

\section{ACKNOWLEDGEMENTS}

The study was done within the framework of the project: Biotechnological conversion of glycerol to polyols and dicarboxylic acids; (No 01.01.02-00-074/09) co-funded by The European Union from The European Regional Development Funds within the framework of the Innovative Economy Operational Programme 2007-2013.

\section{LITERATURE CITED}

1. Nomura, M., Bin, T. \& Nakao, S. (2002). Selective etanol extraction from fermentation broth using a silicate membrane. Separation and Purification Technology, 27, 59-66. DOI: $10.1016 / \mathrm{S} 1383-5866(01) 00195-2$.

2. Hiremath, A., Kannabiran, M. \& Rangaswamy, V. (2011). 1,3-Propanediol production from crude glycerol from jatropha biodiesel process, New Biotechnology, 28, 19-23. DOI:10.1016/j.nbt.2010.06.006.

3. Barnard, G.W. \& Hall, D.O. 1983. Energy from renewable resources, in: H. Dellweg (Ed.), Biotechnology, Verlag Chemie $\mathrm{GmbH}$, Weinhei, vol.3, 593-625.

4. Gyamerah, M. \& Glover, J. (1996). Production of ethanol by continuous fermentation and liquid-liquid extraction, J. Chem. Technol. Biotechnol. 66, 145-152.

5. Bai, F.W., Anderson, W.A. \& Moo-Young, M. (2008). Ethanol fermentation technologies from sugar and starch feedstocks Biotechnology Advances 26, 89-105. DOI:10.1016/ j.biotechadv.2007.09.002.

6. Lipnizki, F. (2010). Membrane process opportunities and challenges in the bioethanol industry, Desalination, 250, 1067-1069. DOI:10.1016/j.desal.2009.09.109.

7. Lawson, K.W. \& Lloyd, D.R. (1997). Membrane distillation, J. Membr. Sci., 124(1), 1-25.

8. Gryta, M. (1997), Influence of polypropylene membrane surface porosity on the performance of membrane distillation process, J. Membr. Sci. 287, 67-78. DOI:10.1016/ j.memsci.2006.10.011.

9. Mannella, G.A., La Carrubba, V. \& Brucato, V. (2010). Characterization of hydrophobic polymeric membranes for membrane distillation process, Int J Mater Form. 3, 563-566. DOI: $10.1007 / \mathrm{s} 12289-010-0832-\mathrm{y}$.

10. Gostoli, C. \& Bandini, S. (1995). Gas membrane extraction of ethanol by glycols: experiments and modeling, $J$. Membr. Sci. 98, 1-12.

11. Gryta, M. (2001), The fermentation process integrated with membrane distillation. Separation and Purification Technology, 24, 283-296. DOI:10.1016/S1383-5866(01)00132-0.

12. Gryta, M., Morawski, A.W. \& Tomaszewska, M. (2000), Ethanol production in membrane distillation bioreactor. Catalysis Today. 56, 159-165. DOI: 10.1016/S0920-5861(99)00272-2.

13. Gryta, M. \& Tomaszewska, M. (1998), Heat transport in the membrane distillation process, J. Membr. Sci. 144, 211-222. DOI:10.1016/j.desal.2007.05.019.

14. Bańkowski, K.. (1974). Physico-chemical Guide, (2nd ed.). Warszawa: Wydawnictwo Naukowo-Techniczne, (in Polish). 